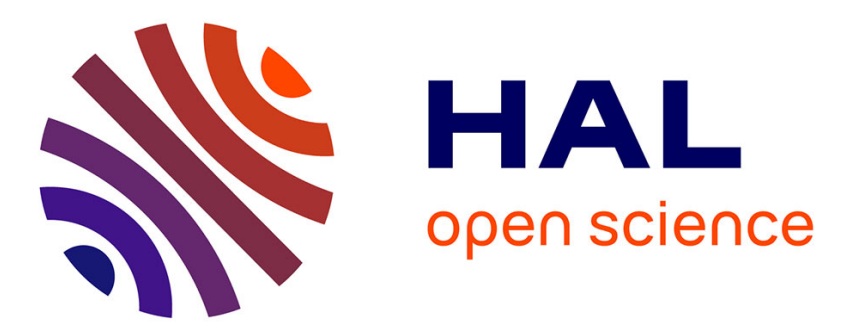

\title{
Kinetics Oxidation of Heavy Oil. 2. Application of Genetic Algorithm for Evaluation of Kinetic Parameters
}

Alexandre Lapene, Gérald Debenest, Michel Quintard, Louis M. Castanier, Margot G. Gerritsen, Anthony R. Kovscek

\section{- To cite this version:}

Alexandre Lapene, Gérald Debenest, Michel Quintard, Louis M. Castanier, Margot G. Gerritsen, et al.. Kinetics Oxidation of Heavy Oil. 2. Application of Genetic Algorithm for Evaluation of Kinetic Parameters. Energy \& Fuels, 2015, vol. 29 ( $\mathrm{n}^{\circ}$ 2), pp.1119-1129. 10.1021/ef501392k . hal-01130138

\author{
HAL Id: hal-01130138 \\ https://hal.science/hal-01130138
}

Submitted on 11 Mar 2015

HAL is a multi-disciplinary open access archive for the deposit and dissemination of scientific research documents, whether they are published or not. The documents may come from teaching and research institutions in France or abroad, or from public or private research centers.
L'archive ouverte pluridisciplinaire HAL, est destinée au dépôt et à la diffusion de documents scientifiques de niveau recherche, publiés ou non, émanant des établissements d'enseignement et de recherche français ou étrangers, des laboratoires publics ou privés. 


\section{Open Archive TOULOUSE Archive Ouverte (OATAO)}

OATAO is an open access repository that collects the work of Toulouse researchers and makes it freely available over the web where possible.

This is an author-deposited version published in : http://oatao.univ-toulouse.fr/ Eprints ID : 13613

To link to this article : DOI:10.1021/ef501392k

URL : http://dx.doi.org/10.1021/ef501392k

\section{To cite this version :}

Lapene, Alexandre and Debenest, Gérald and Quintard, Michel and Castanier, Louis M. and Gerritsen, Margot G. and Kovscek, Anthony R. Kinetics Oxidation of Heavy Oil. 2. Application of Genetic Algorithm for Evaluation of Kinetic Parameters. (2015) Energy \& Fuels, vol. 29 (n²). pp. 1119-1129. ISSN 0887-0624

Any correspondance concerning this service should be sent to the repository administrator: staff-oatao@ listes-diff.inp-toulouse.fr 


\title{
Kinetics Oxidation of Heavy Oil. 2. Application of Genetic Algorithm for Evaluation of Kinetic Parameters
}

\author{
Alexandre Lapene, ${ }^{*}{ }^{\dagger}$, Gérald Debenest, $^{\S}$ Michel Quintard, ${ }^{\S, \perp}$ Louis M. Castanier, ${ }^{\dagger}$ Margot G. Gerritsen, ${ }^{\dagger}$ \\ and Anthony R. Kovscek ${ }^{\dagger}$ \\ ${ }^{\dagger}$ Energy Resources Engineering, Stanford University, Stanford, California 94305, United States \\ ${ }^{\S}$ Université de Toulouse; INPT, UPS; IMFT (Institut de Mécanique des Fluides de Toulouse); Allée Camille Soula, F-31400 \\ Toulouse, France \\ ${ }^{\perp}$ CNRS; IMFT; F-31400 Toulouse, France
}

ABSTRACT: In-situ combustion (ISC) is the process of injecting air into oil reservoirs to oxidize part of the crude oil and has been utilized for both light oil and heavy oil. The viscosity of the remaining crude oil is reduced by the significant heat generated from combustion reactions, which contributes to enhanced oil recovery. In the first paper in this series [Lapene et al., Energy Fuels 2011, 25, 4886-4895], we developed a new method to interpret ramped temperature oxidation (RTO) experiments, using a reactor model based on a compositional and full equation-of-state approach. In this work, we use this RTO reactor model, coupled with an optimization tool, to determine the optimal kinetic parameters for an extra heavy oil reservoir. Kinetic parameters are commonly determined using analytical methods and limited data. Typically, only one type of observational data (for example, oxygen consumption) is used from one experiment. Here, we use two series of experiments data- namely, $\mathrm{CO}_{2}$ and $\mathrm{O}_{2}$ concentrations - and a multiobjective approach to obtain kinetic parameters for the different combustion reactions. Finally, we obtain a set of possible kinetic schemes, accouting for all mechanisms, such as reactions, phase changes, and transport processes.

\section{INTRODUCTION}

The reaction kinetics for heavy oil combustion has been studied for several decades. In early work, the reaction models were derived mostly based on the controlled heating and combustion of a small sample of oil, ${ }^{1-4}$ either under constant temperature or in ramped temperature oxidation (RTO). The flue gas is analyzed to determine the concentrations of carbon dioxide, carbon monoxide, and oxygen from which kinetic parameters can be deduced. Most early studies limited the oxidation reactions to low-temperature oxidation (LTO) and hightemperature oxidation (HTO).$^{5-7}$ Improved understanding of LTO and HTO reactions was provided in the report by Moore. ${ }^{8}$ Oxidation reactions were shown to be oil-dependent, and a clear separation between LTO and HTO was observed, in terms of temperature range, with an observed decreased oxygen consumption between the LTO and HTO temperature regions, which is now known as the negative temperature gradient region.

The LTO reactions, in most cases, produce oxygenated compounds, such as carboxylic acids, aldehydes, ketones, alcohols and hyperoxides, ${ }^{5}$ but they can also give carbon oxide gases and water. The HTO reactions essentially produce carbon monoxide, carbon dioxide, and water through the combustion of fuel deposited in lower-temperature regimes. Bousaid and Ramey ${ }^{1}$ considered this fuel to be a solid resembling carbon (i.e, coke), formed via the pyrolysis of crude oil. Other researchers ${ }^{7,9}$ believed that the fuel mainly consists of heavy low-volatility hydrocarbon fractions that are left behind by distillation. The exact reaction mechanisms are still under strong debate, complicated by the fact that the ISC combustion behavior strongly varies between oils, as well as reservoir conditions, such as the presence of clay or metallic salt in the reservoir rock. $^{10}$

Recently, we classified and analyzed all kinetic experiments available in the literature, and we argued that kinetic cell experiments are well-suited to guide the selection of kinetic parameters. ${ }^{11}$ However, the optimal way to derive kinetic parameters from the experiments is still an open question. In 1984, Fassihi et al. ${ }^{12}$ proposed using an analytical model. Under various assumptions and experimental conditions that are not always possible to realize, kinetic parameters can be found by graphic integration. Apart from the challenge in meeting all necessary conditions, classical methods also involve just the oxygen signal in just one experimental setting. The isoconversional method proposed by Cinar et al. ${ }^{13}$ offers an approach to effectively include more than one experimental setup (varying heating rates) and gives the apparent activation energy as a function of temperature, which is an improvement. But classical methods also do not take into account the behavior of other gases, which is often necessary (see, for instance, Khansari et al. $\left.{ }^{14}\right)$. For instance, reactions occurring during oil combustion involve oxygen addition reactions as well as classical oxidation reactions. The only way to distinguish oxygen addition reactions from classical oxidation reactions is to look at carbon monoxide and carbon dioxide production, because these are not produced by oxygen addition reactions.

In this work, our objective is to develop a more general approach that uses multiobjective optimization to examine a 
variety of experimental data, as well as experimental settings, which we believe is necessary to improve the quality of the kinetic models. In the examples presented, we take into account oxygen production data and carbon dioxide production data. Both data sources provide unique information about the kinetics. Therefore, the optimization approach must include two independent objective functions. Because the objective functions may have opposing gradient directions, the solution cannot be expected to be unique. Instead, a set of optimal solutions will be found, each leading to a different kinetic model, yet all fitting the given data.

The present study builds on the work presented in our earlier work, ${ }^{11}$ in which a new simulator was described that is specially designed for kinetic cell experiments. Here, we use this simulator in a multiobjective genetic algorithm to derive optimal kinetic parameters. As an example of its efficiency, we applied the new proposed method on a real case. Two objective functions built with oxygen and carbon dioxide evolution are chosen. Experimental data are provided from a previous paper. $^{15}$

\section{MULTIOBJECTIVE GENETIC ALGORITHM FOR KINETIC STUDY}

Multiobjective Optimization. Historically, optimization techniques first treated multiobjective problems by combining the individual objectives into one, either through a weighted sum $^{16}$ or, when possible, by transforming one of the objective functions into a single response function constrained by the others. This allows for the use of a classical single-objective optimization algorithm to treat the multiobjective problem. However, such approaches provide only one solution, whereas in the case of multiobjective optimization, more solutions may exist. Another complication is that the optimal solutions for the individual objective functions may vary. Therefore, the best solution, or solutions, are not optimal for each and every objective function. In this work, we find solutions that are optimal in the sense of Pareto. A solution $\left(x^{*}\right)$ is a Pareto optimum for a $k$-objective optimization problem, if, for $I=\{1$, $2, \ldots, k\}$ and for all $x$,

$$
\forall i \in I, f_{i}(x)=f_{i}\left(x^{*}\right) \quad \text { or } \quad \exists i \in I \mid f_{i}(x)>f_{i}\left(x^{*}\right)
$$

The optimization process gives rise to a set of optimal solutions. Each solution of this set is optimal: no improvement can be found in one criterion without degrading another. This set of optimal solutions is called the Pareto front. All of these solutions are said to be nondominated. Here, a solution A dominates a solution $B$ if and only if

$$
\forall i \in I, f_{i}(\mathrm{~A}) \leq f_{i}(\mathrm{~B}) \quad \text { and } \quad \exists i \in I \mid f_{i}(\mathrm{~A})<f_{i}(\mathrm{~B})
$$

Figure 1 is an illustration of a Pareto front for a generic twoobjective problem.

Earlier, several multiobjective optimization problems in chemical engineering were studied, in the areas of reactions engineering ${ }^{19}$ and mass transfers. ${ }^{18}$ A detailed review is given in the work of Bhaskar et al. ${ }^{19}$ Evolutionary algorithms are the most popular, because the objective functions can be built using black-box numerical codes. In this work, we focus on genetic algorithms. Genetic algorithms are attractive because they do not require gradient information, which means they can be applied to a large range of objective functions and constraints (also see the review of algorithms for multiobjective optimization in the report by Marler and Arora ${ }^{20}$ ). For a

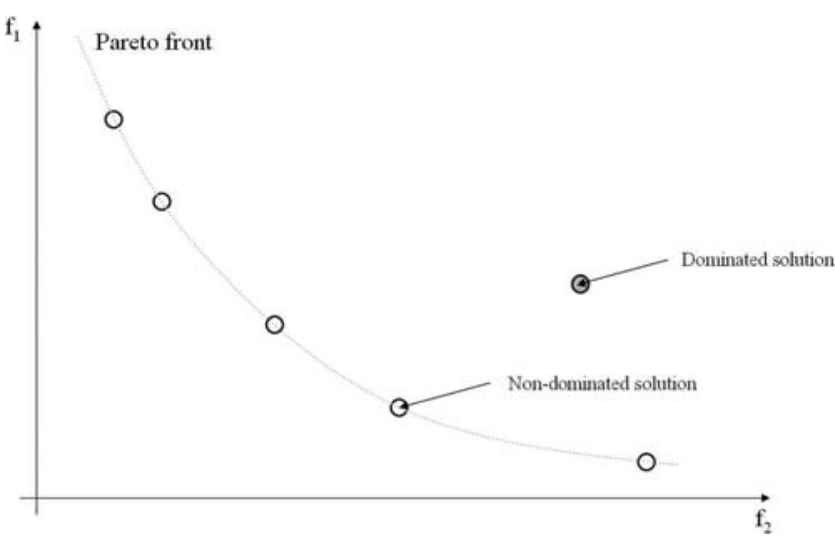

Figure 1. Example of Pareto front on a two-objective problem.

one-objective optimization problem, a gradient-based method could be used. However, we prefer genetic algorithms, because the optimization problems studied here, which rely on experimental and numerical data, typically lead to rough response surfaces. Gradient-based optimization methods do not work well with such surfaces. Besides, gradient-based optimization algorithms are at higher risk of not reaching a global solution, because they can get stuck in local minima. Finally, genetic algorithms are also attractive, because they are inherently parallel.

All genetic algorithms, for both single-objective and multiobjective problems, follow the same global structure:

(1) A population of $N$ individuals is randomly generated. The individuals are characterized by the variables of the problem $(s)$.

(2) The objective function(s) is (are) evaluated for each individual.

(3) Some individuals in the population are selected for the next generation. All of them or only a few are modified by crossing-over operations and mutations.

(4) The process is repeated from step 2, or stopped if a convergence criterion or a given maximum number of generations is reached.

One of the earliest multiobjective genetic algorithms is VEGA (Vector Evaluated Genetic Algorithm). ${ }^{21}$ In this approach, for a $k$-objective problem, a population of $N$ individuals is divided in $k$ subpopulations, and each subpopulation is associated with one objective. Populations are then aggregated and crossing-over and mutation operators are applied. To improve on VEGA, and to determine a better coverage of the Pareto front, many other multiobjectives algorithms have been developed, such as the niched Pareto genetic algorithms (NPGA), ${ }^{22}$ the strength Pareto evolutionary algorithms (SPEA and SPEA2), ${ }^{23,24}$ the nondominated sorting genetic algorithm (NSGA), ${ }^{25}$ and the NSGA-II proposed by Deb et al. ${ }^{26}$

NSGA-II is the algorithm that has found the widest application and has undergone the deepest investigation. Compared to its predecessor (NSGA), NSGA-II is more efficient. It uses an elitist approach that allows the best solutions between two generations to be preserved. A special sorting procedure makes it faster and more reliable. Selection is done considering a crowding distance in order to promote odd solutions and avoid niching. Finally, compared to other algorithms, NSGA-II does not require any parameter tweaking. For these reasons, NSGA-II is selected for this study. 
Algorithm Structure. We choose to use real coding, rather than binary coding, because it is more convenient for data handling and has improved robustness, provided that appropriate crossing-over and mutation operators are used. ${ }^{27}$

The algorithm that we proposed to use for this study is structured as below.

(1) A population of $N$ individuals is randomly generated. It is characterized by kinetic parameters.

(2) Objective functions for each individual are evaluated by a comparison between experimental and numerical kinetic cell results.

(3) Sorting and crowding distance calculation are performed as described in Deb et al. ${ }^{26}$

(4) The best $N / 2$ individuals of the population are kept for the next generation, based on previous sorting and crowding distance values.

(5) Two individuals are selected from the remaining population, according to a predefined selection operator, and crossed over to provide two new offsprings. According to a given probability, each offspring may mutate. Step 5 is repeated until the population is again at $N$ individuals.

(6) The process is repeated from step 2, unless the maximum number of iterations is reached.

In the Deb et al. paper, ${ }^{26}$ the first generation is produced in a special way, different from the later generations. Here, this is unnecessary, and, hence, we leave it out. An extra advantage of leaving this out is that the algorithm is more versatile: it can address single-objective problems easily by modifying the selection operator and setting the size of the elitist population to one.

Objective Function. The objective functions are built considering experimental data $\left(D^{\mathrm{E}}\right)$ and numerical results $\left(D^{\mathrm{N}}\right)$ for a given set of parameters $(x)$. For instance, the set of parameters can represent kinetic parameters such as preexponential factors and/or activation energies for each reaction. The Euclidian norm is chosen, and so the objective function is defined as

$$
\mathcal{F}(x)=\sqrt{\sum_{\mathrm{t}}\left[D^{\mathrm{E}}\left(t_{i}\right)-D^{\mathrm{N}}\left(t_{i}\right)\right]^{2}}
$$

with $N_{m}$ is the dimension of $\mathbf{D}^{\mathrm{E}}$ and $\mathbf{D}^{\mathrm{N}}, D_{i}^{\mathrm{E}} \in \mathbf{D}^{\mathrm{E}}, D_{i}^{\mathrm{N}} \in \mathbf{D}^{\mathrm{N}}$ and $\mathbf{t}=\left[t_{0}, \ldots, t_{f}\right]$. Here, $t_{0}$ and $t_{f}$ are, respectively, the start and end time of the experiment.

In a classical kinetic cell experiment, the experimental results typically show two peaks in the flue gas composition profiles, corresponding to LTO and HTO, respectively. For heavy oil, the LTO peak is usually lower than the HTO peak. If the objective functions are based on the variation of the flue gas composition and defined by eq 3 , the first peak may be penalized. However, from a physical point of view, it is important to consider both peaks with equal importance. If the experimental solution involves $N_{\mathrm{p}}$ peaks, the $n$th peak is located in $I_{n}=\left[t_{n}, \ldots, t_{n+1}\right]$. Then, if we define $M_{n}$ as $\max _{I_{n}}\left(\mathbf{D}^{\mathrm{E}}\right)$, the objective function is redefined as

$$
\mathcal{F}^{*}(x)=\sqrt{\sum_{n=1}^{N_{\mathrm{p}}} \sum_{I_{n}}\left[\frac{D^{\mathrm{E}}\left(t_{i}\right)-D^{\mathrm{N}}\left(t_{i}\right)}{M_{n}}\right]^{2}}
$$

Sorting and Crowding Distance. Sorting and crowding are done according to Deb et al. ${ }^{26}$ The multiobjective genetic algorithm implemented is the nondominated sorting. We order the population into a hierarchy of nondominated Pareto fronts. Then, we calculate the average distance between members of each front on the front itself.

Crossing-Over Operator. For convenience, we use the same crossing-over operator as that in binary coding. If $\mathrm{A}$ and $\mathrm{B}$ are two individuals and $\mathrm{A}^{\prime}$ and $\mathrm{B}^{\prime}$ are their offspring, we can transform $\mathrm{A}$ and $\mathrm{B}$ as follows:

$$
\begin{aligned}
& \mathrm{A}=\left(\begin{array}{c}
y_{1} \\
y_{2} \\
\vdots \\
y_{i} \\
y_{i+1} \\
\vdots \\
y_{n-1} \\
y_{n}
\end{array}\right) \text { and } \mathrm{B}=\left(\begin{array}{c}
x_{1} \\
x_{2} \\
\vdots \\
x_{i} \\
x_{i+1} \\
\vdots \\
x_{n-1} \\
x_{n}
\end{array}\right) \stackrel{\text { crossing-over }}{\longrightarrow} \\
& \mathrm{A}^{\prime}=\left(\begin{array}{c}
y_{1} \\
y_{2} \\
\vdots \\
y_{i} \\
x_{i+1} \\
\vdots \\
x_{n-1} \\
x_{n}
\end{array}\right) \text { and } \mathrm{B}^{\prime}=\left(\begin{array}{c}
x_{1} \\
x_{2} \\
\vdots \\
x_{i} \\
y_{i+1} \\
\vdots \\
y_{n-1} \\
y_{n}
\end{array}\right)
\end{aligned}
$$

Here, $x_{i}$ and $y_{i}$ are the genes of $\mathrm{A}$ and $\mathrm{B}$, respectively, and they characterize the variables of the optimization problem. This crossing-over operator is called the binary simple-point operator, because only one point is used to switch genes. Multipoint operators can be also used.

For real coding genetic algorithms, the binary approach is not exactly applicable, because, in real coding, the nick occurs between two variables, whereas in the binary case, bits are used, which means that the nick can be located in the middle of a gene. Thus, for real coding, this type of operator does not create new variables but simply permutes them. Specific operators have been created for real coding genetic algorithm in order to overcome this problem. Most of them are based on a linear combination of several variables. One of the most used is the arithmetical crossing-over operator introduced by Eshelman and Schaffer. ${ }^{28}$ For two genes $x$ and $y$, the operator transforms them to $x^{\prime}$ and $y^{\prime}$ as follows:

$$
\left\{\begin{array}{l}
x^{\prime}=\alpha x+(1-\alpha) y \\
y^{\prime}=\alpha y+(1-\alpha) x
\end{array}\right.
$$

where $\alpha$ is a random number in $[0,1]$. However, if $x<y$ then $x^{\prime}$ and $y^{\prime}$ are always in $[x, y]$. This restriction is not present in the binary coding operator. To alleviate this shortcoming, Sefrioui ${ }^{29}$ proposed a new operator. For two genes $x$ and $y$, the operator transforms them to $x^{\prime}$ and $y^{\prime}$ as 
Table 1. Review of the Reaction Mechanisms ${ }^{a}$ Presented in the Literature

\begin{tabular}{|c|c|c|c|c|c|c|c|c|c|c|}
\hline & $\mathrm{CL}$ & POL & OOC & $\mathrm{CR}$ & CCG & $\mathrm{CI}$ & $\mathrm{CC}$ & $\mathrm{CO}$ & $\mathrm{CH}$ & $\mathrm{CO} 2 \mathrm{O}$ \\
\hline Verma et al. $^{36}$ & & & & $x$ & $x$ & & $x$ & $x$ & & \\
\hline Crookston et al. ${ }^{38}$ & $x$ & & & $x$ & & & $x$ & & $x$ & \\
\hline Adegbesan et al., ${ }^{39}$ only for LTO & & & & $x$ & & & $x$ & & & \\
\hline Kumar $^{40}$ & $x$ & & & $x$ & & & $x$ & & $x$ & \\
\hline Akin et al. ${ }^{37}$ & $x$ & & & $x$ & $x$ & & $x$ & & $x$ & $x$ \\
\hline Kuhlman $^{32}$ & $x$ & & & $x$ & & $x$ & & & $x$ & \\
\hline Freitag and Verkoczy, ${ }^{33}$ Freitag and Exelby, ${ }^{41}$ and Ren et al. ${ }^{42}$ & & $x$ & $x$ & $x$ & & & $x$ & & $x$ & \\
\hline
\end{tabular}

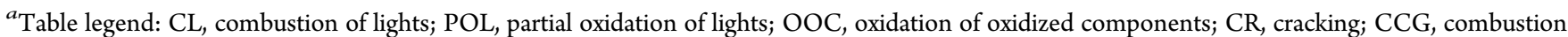
of cracking gas; CI, combustion of intermediates; $\mathrm{CC}$, combustion of coke; $\mathrm{CO}$, combustion of oil; $\mathrm{CH}$, combustion of heavies; and $\mathrm{CO}_{2} \mathrm{O}, \mathrm{CO}_{2}$ oxidation.

$$
\begin{aligned}
& \left\{\begin{array}{l}
x^{\prime}=\alpha(M-m)+m \\
y^{\prime}=\alpha(M-m)+m
\end{array}\right. \text { with } \\
& \left\{\begin{array}{l}
m=\min (x, y)-\lambda|\max (x, y)-\min (x, y)| \\
M=\max (x, y)+\lambda|\max (x, y)-\min (x, y)|
\end{array}\right.
\end{aligned}
$$

where $\lambda$ is a constant value set by the user. Here, if $x<y$, then $x^{\prime}$ and $y^{\prime}$ are in $[m, M]$ while $m<x$ and $M>y$. Because our problem is constrained, $m$ and $M$ are eventually adjusted. For the rest of this paper, $\lambda$ is set to 0.3666 , according to Sefrioui. ${ }^{29}$ The crossing-over operator is applied to all the genes of the parents.

Mutation Operator. In binary coding genetic algorithms, the mutation operator just converts one or several bits. Because a gene is characterized by a large number of bits, the changes are not large and, compared to the crossing-over operator, the mutation operator does not play an important role. For the real coding algorithm, the mutation operator is still the cornerstone of the exploration process, although important efforts have been made on crossing-over operator in order to enhance its exploration capability. ${ }^{30}$ Its structure is more complex than that observed for binary coding algorithms. We decided to select a mutation operator presented by Janikow and Michalewicz. ${ }^{31}$ If a gene $y$ undergoes a mutation, its new value would be in $\left[\operatorname{Min}_{y}\right.$, $\mathrm{Max}_{y}$ ], which corresponds to the constraints on the variable $y$. This new value is calculated as

$$
y^{\prime}=\left\{\begin{array}{lc}
y+\Delta\left(t, \operatorname{Max}_{y}-y\right) & \text { if } \Gamma=0 \\
-\Delta\left(t, y-\operatorname{Min}_{y}\right) & \text { if } \Gamma=1
\end{array}\right.
$$

where $t$ is the generation number for the genetic algorithm and $\Gamma$ a boolean. The parameter $\Delta(t, y)$ is defined as

$$
\Delta(t, y)=y r\left(1-\frac{t}{T}\right)^{b}
$$

where $r$ is a random number in $[0,1], T$ the maximum number of generations, and $b$ a refinement parameter. The $\Delta$ function is built in such a way that it tends to 0 as $t$ tends to $T$ in order to enhance exploration for first generations and to narrow it for last generations. Parameter $b$ controls the impact of the mutation. The larger it is, the more the mutation creates values far away from the original value. Preliminary tests have shown that a value of $b=5$ is a good compromise.
Table 2. Properties of Oxidized Components

$\begin{array}{lrccc}\text { component } & M_{\mathrm{w}}(\mathrm{g} / \mathrm{mol}) & P_{\mathrm{c}}(\text { bar }) & T_{\mathrm{c}}(\mathrm{K}) & \omega \\ \mathrm{C}_{2}-\mathrm{C}_{11 \text { ox }} & 687.75 & 13 & 900 & 1 \\ \mathrm{C}_{12}-\mathrm{C}_{160 \mathrm{x}} & 925.66 & 12 & 930 & 1 \\ \mathrm{C}_{17}-\mathrm{C}_{21 \mathrm{ox}} & 1244.04 & 10 & 950 & 1 \\ \mathrm{C}_{22}-\mathrm{C}_{27 \mathrm{ox}} & 15914.01 & 7 & 1050 & 1.5 \\ \mathrm{C}_{28}-\mathrm{C}_{35 \mathrm{ox}} & 2037.67 & 6.1 & 1120 & 1.6 \\ \mathrm{C}_{36}-\mathrm{C}_{49 \mathrm{ox}} & 2712.89 & 6 & 1160 & 1.6\end{array}$

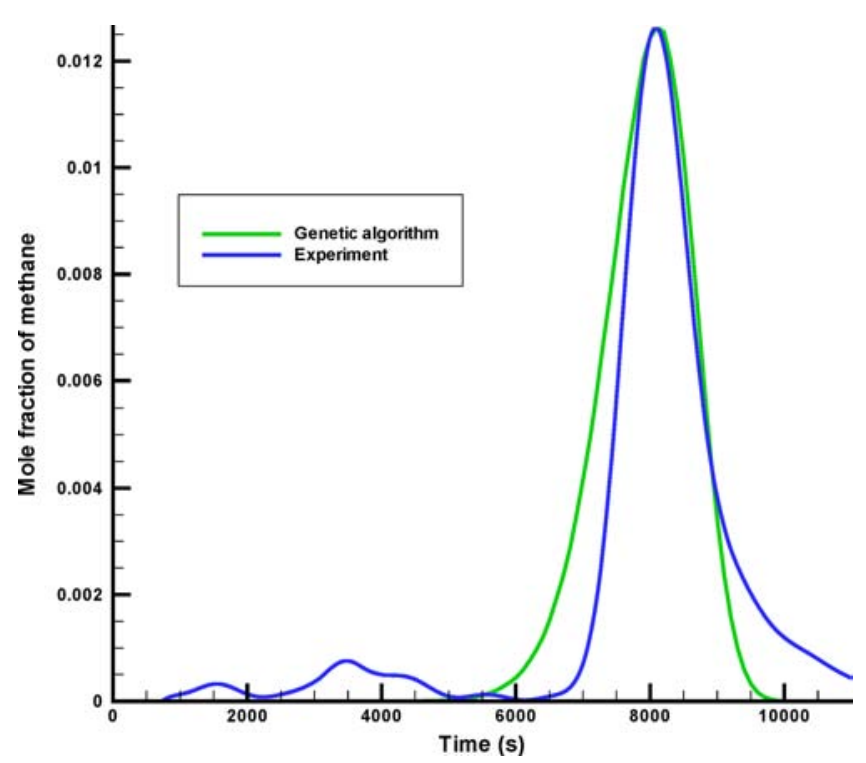

Figure 2. Comparison between experimental results and numerical results from the genetic algorithm.

\section{EVALUATION OF KINETIC PARAMETERS FROM KINETIC CELL EXPERIMENTS}

The experimental data used for this study come from Lapene et al. ${ }^{15}$ Several kinetic cell experiments have been performed; however, in this paper, we only use the experiments labeled as RUN 10 and RUN 12. In all of the experiments used for the purpose of this work, the temperature controller is trimmed to reach $650{ }^{\circ} \mathrm{C}$ in $250 \mathrm{~min}$ at a constant rate of increase. RUN 10 is a two-stage experiment. First, the oil is heated to crack all the residue into solid coke. Then, a classical kinetic experiment is performed to burn the resulting coke sample. RUN 12 is a classical kinetic cell experiment performed on the original heavy oil component without any pretreatment. More details can be found in Lapene et al. ${ }^{15}$

The kinetic cell simulator developed in our previous report in this series ${ }^{11}$ is used to build the objective functions (see eq 4). 


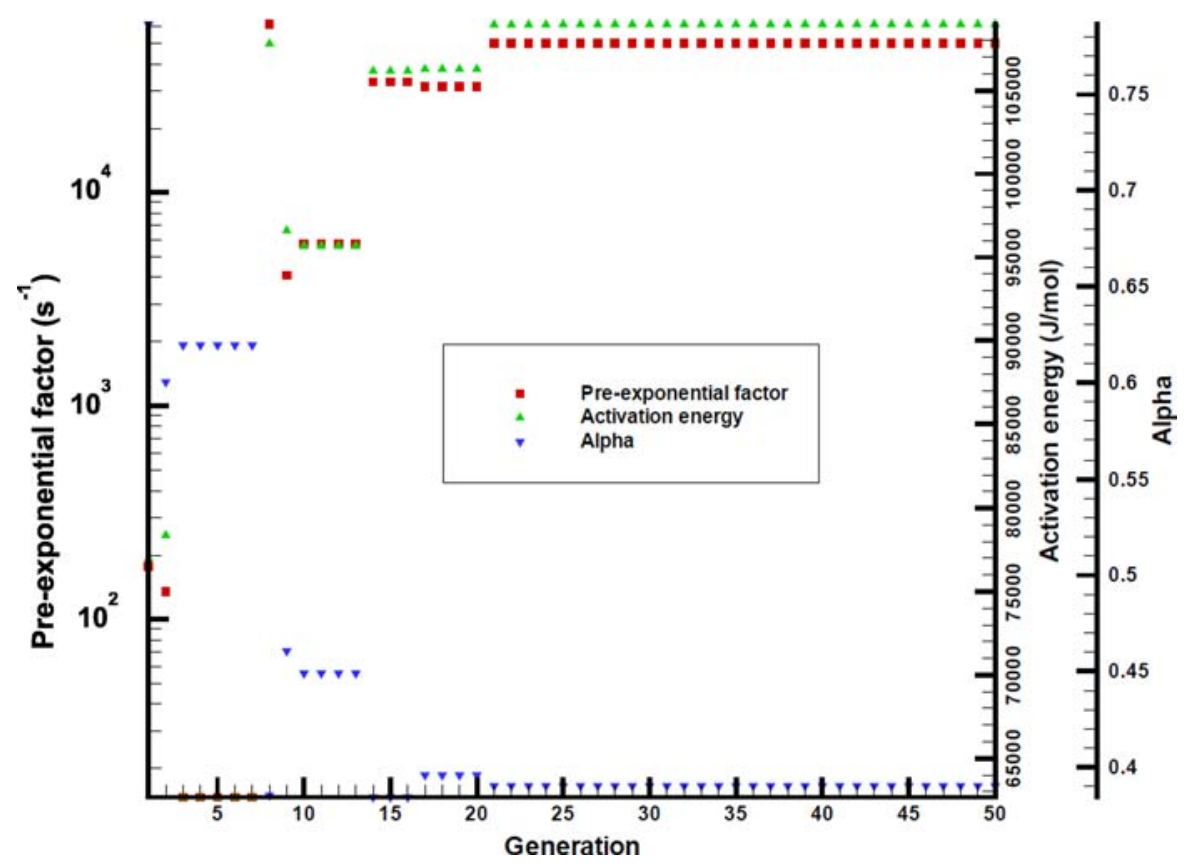

Figure 3. Kinetic parameters $(\alpha$, activation energy $(E)$, and pre-exponential factor $(A))$ versus generation.

Table 3. Final Kinetic Parameters (Relative to Figure 3)

\begin{tabular}{ll}
\multicolumn{1}{c}{ parameter } & \multicolumn{1}{c}{ value } \\
activation energy, $E$ & $108969 \mathrm{~J} / \mathrm{mol}$ \\
pre-exponential factor, $A$ & $5.00928 \times 10^{4} \mathrm{~s}^{-1}$ \\
$\alpha$ & 0.390294 \\
\hline
\end{tabular}

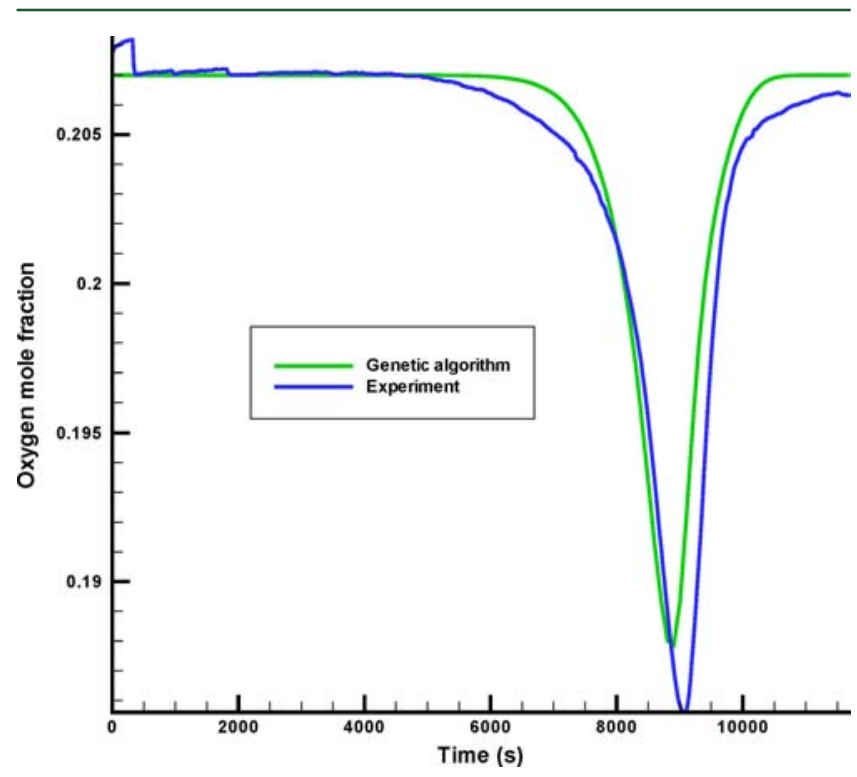

Figure 4. Comparison between numerical and experimental results.

We note that temperature profiles generated by the laboratory experiments are given to the simulator as inputs. That is, temperature is not solved for explicitly, nor is it matched as part of the multiobjective algorithm. This has two advantages. The first advantage is that the numerics track the experiments closely: any deviations from the linear temperature profile during the experiments are taken into account. The second advantage is that the number of degrees of freedom in the

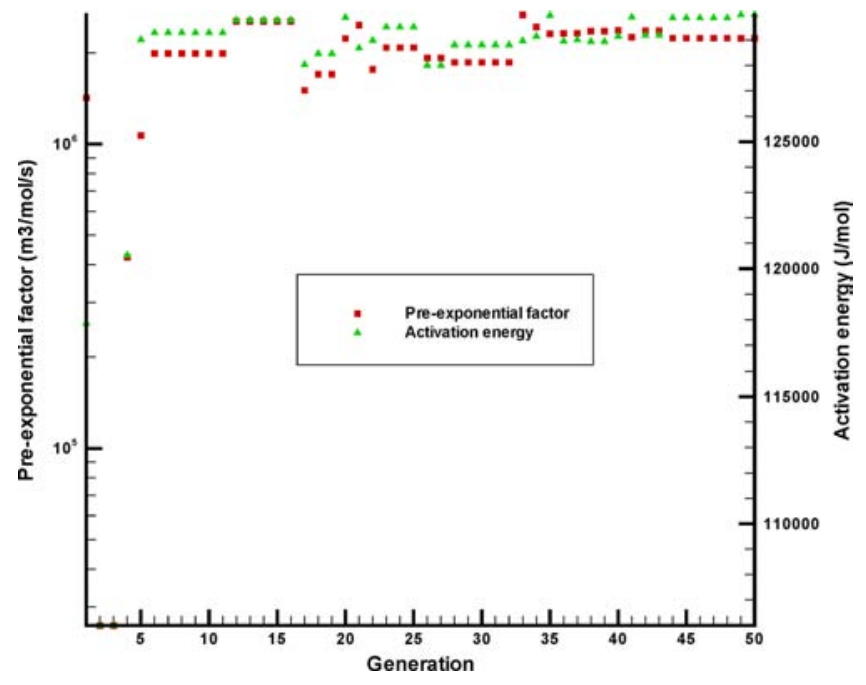

Figure 5. Kinetic parameters (activation energy $(E)$ and preexponential factor $(A))$ versus generation.

Table 4. Final Kinetic Parameters (Relative to Figure 5)

\begin{tabular}{cc}
\multicolumn{1}{c}{ parameter } & \multicolumn{1}{c}{ value } \\
activation energy, $E$ & $129993 \mathrm{~J} / \mathrm{mol}$ \\
pre-exponential factor, $A$ & $2.230453 \times 10^{6} \mathrm{~m}^{3} /(\mathrm{mol} / \mathrm{s})$ \\
\hline
\end{tabular}

optimization problem does not further increase, making the problem more computationally tractable.

In our previous work, ${ }^{11}$ we recommended performing onedimension simulations and using real flash calculations for phase equilibria. According to mesh sensitivity tests, and as a good compromise between accuracy and decent computation times, we decided to use a three-block mesh. During the optimization process, the kinetic cell code is called several times; this represents the main computational cost.

In the literature, there is no agreement about which reaction mechanism most reliably describes the ISC processes. Indeed, 


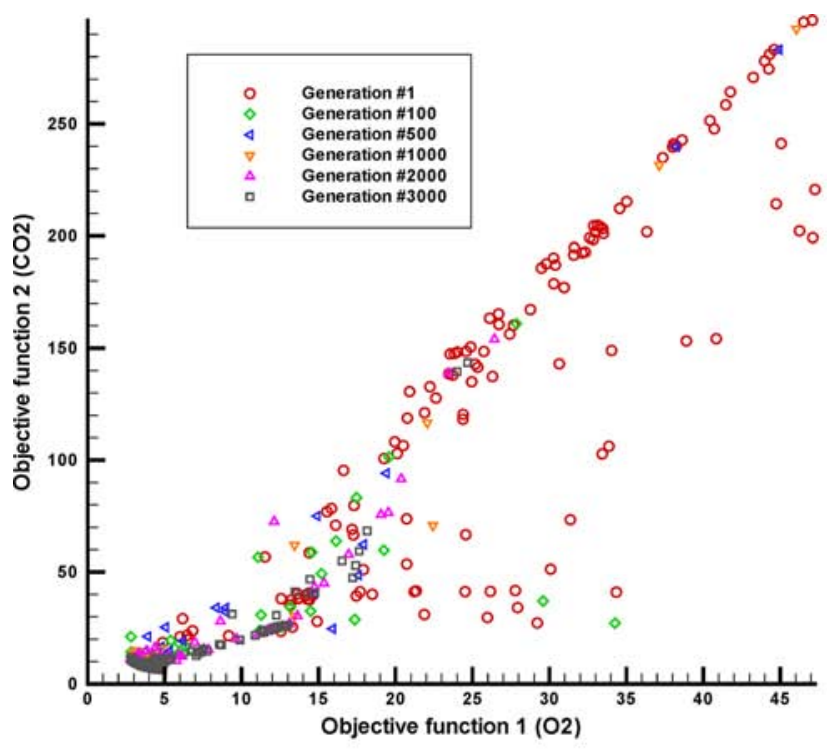

(a) Overview

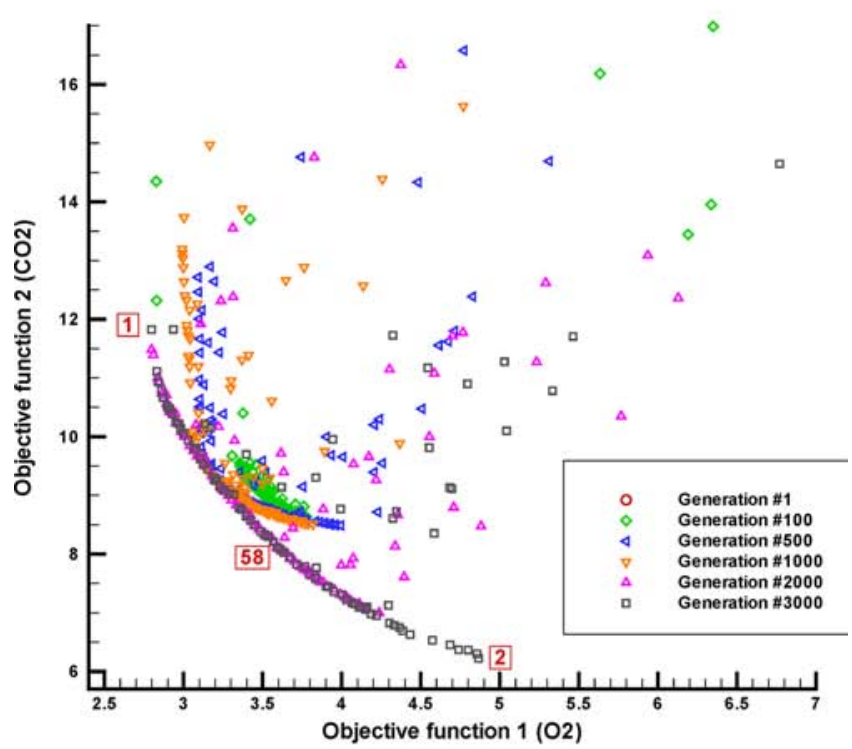

(b) Enlarging

Figure 6. Evolution of objective function built on oxygen $\left(\mathrm{O}_{2}\right)$ data versus objective function build on carbon dioxide $\left(\mathrm{CO}_{2}\right)$ data.

many different reaction mechanisms are proposed, and the most popular ones are listed in Table 1 . However, there are similarities. First, all of them include a cracking reaction. Fuel formation reactions transform a heavy component to coke or light components or both. It is typically followed by a coke combustion reaction, except in the work by Kuhlman. ${ }^{32}$ In addition to the coke combustion, which occurs at high temperature, most of the authors proposed the combustion of the heavy components. For LTO, there is no clear trend. Some of the reaction mechanisms include the combustion of light components, whereas Freitag and Verkoczy, ${ }^{33}$ Freitag and Exelby, ${ }^{34}$ and Ren et al. ${ }^{35}$ described the LTO reactions as a two-step reaction with partial oxidation of light components in the first step, followed by the oxidation of the products. This choice was motivated by observations in the work of Burger and Sahuquet ${ }^{5}$ and Mamora et al. ${ }^{7}$ Finally, Verma et al. ${ }^{36}$ and Akin et al. ${ }^{37}$ take into account the homogeneous combustion of cracking gases.

For the oil used in our experiments, we propose the following reaction mechanisms:

$$
\begin{aligned}
& \mathrm{C}_{50+(\mathrm{c})} \stackrel{R_{1}}{\rightarrow} \mathrm{C}_{1}+\text { coke } \\
& \text { coke }+\mathrm{O}_{2} \stackrel{R_{2}}{\rightarrow} \mathrm{CO}+\mathrm{CO}_{2}+\mathrm{H}_{2} \mathrm{O} \\
& \mathrm{C}_{2}-\mathrm{C}_{11} \\
& \mathrm{C}_{12}-\mathrm{C}_{16} \\
& \mathrm{C}_{17}-\mathrm{C}_{21}-\mathrm{C}_{27}+\mathrm{O}_{2} \stackrel{R_{3}}{\rightarrow} \mathrm{CO}+\mathrm{CO}_{2}+\mathrm{H}_{2} \mathrm{O} \\
& \mathrm{C}_{28}-\mathrm{C}_{35} \\
& \mathrm{C}_{36}-\mathrm{C}_{49} \\
& \mathrm{C}_{2}-\mathrm{C}_{11} \quad \mathrm{C}_{2 \mathrm{ox}}-\mathrm{C}_{11 \mathrm{ox}} \\
& \mathrm{C}_{12}-\mathrm{C}_{16} \quad \mathrm{C}_{12 \mathrm{ox}}-\mathrm{C}_{16 \mathrm{ox}}
\end{aligned}
$$

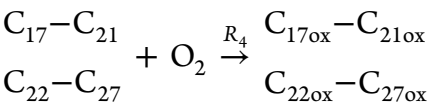

$$
\begin{aligned}
& \mathrm{C}_{28}-\mathrm{C}_{35} \quad \mathrm{C}_{28 \mathrm{ox}}-\mathrm{C}_{35 \mathrm{ox}} \\
& \mathrm{C}_{36}-\mathrm{C}_{49} \quad \mathrm{C}_{36 \mathrm{ox}}-\mathrm{C}_{49 \mathrm{ox}} \\
& \mathrm{C}_{2 \mathrm{ox}}-\mathrm{C}_{11 \mathrm{ox}} \\
& \mathrm{C}_{12 \mathrm{ox}}-\mathrm{C}_{16 \mathrm{ox}} \\
& \mathrm{C}_{17 \mathrm{ox}}-\mathrm{C}_{21 \mathrm{ox}}+\mathrm{O}_{2} \stackrel{R_{5}}{\rightarrow} \mathrm{CO}+\mathrm{C}_{27 \mathrm{ox}}+\mathrm{CO}_{2}+\mathrm{H}_{2} \mathrm{O} \\
& \mathrm{C}_{28 \mathrm{ox}}-\mathrm{C}_{35 \mathrm{ox}} \\
& \mathrm{C}_{36 \mathrm{ox}}-\mathrm{C}_{49 \mathrm{ox}} \\
& \underset{\mathrm{C}_{50+(\mathrm{c})}}{\mathrm{C}_{50+}}+\mathrm{O}_{2} \stackrel{R_{6}}{\rightarrow} \mathrm{CO}+\mathrm{CO}_{2}+\mathrm{H}_{2} \mathrm{O}
\end{aligned}
$$

This mechanism incorporates the main reactions found in the literature. We chose to adopt the atomic description for components, as opposed to the SARA description, because it is compatible with the thermodynamic characterization of the oil. Indeed, it is difficult to attribute critical properties to SARA components. The heavy oil is characterized by eight lumped components as $\mathrm{C}_{1}, \mathrm{C}_{2}-\mathrm{C}_{11}, \mathrm{C}_{12}-\mathrm{C}_{16}, \mathrm{C}_{17}-\mathrm{C}_{21}, \mathrm{C}_{22}-\mathrm{C}_{27}, \mathrm{C}_{28}-$ $\mathrm{C}_{35}, \mathrm{C}_{36}-\mathrm{C}_{49}$, and $\mathrm{C}_{50+}$. Details are given in the first paper in this series. ${ }^{11}$ We note that $\mathrm{C}_{50+}$ is introduced as a heavy end component, necessary for representing the heavy oil in these experiments. As explained in the earlier work, ${ }^{11}$ it is the heaviest component for which we can get thermodynamics properties from the literature. Modeling heavier components is not useful, since the corresponding properties would be highly uncertain.

We assume all reactions are first order with respect to $\left[\mathrm{O}_{2}\right]$. The reaction rates for the oxidation reactions are given by the Arrhenius law: 


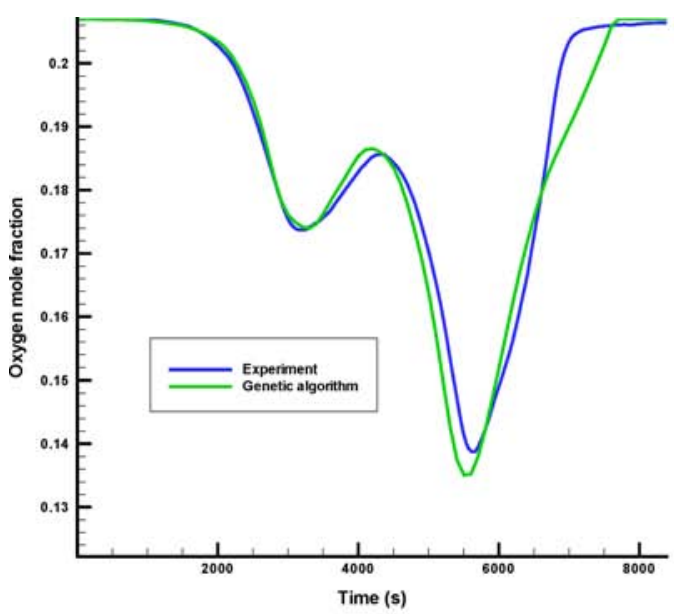

(a) \#1 - Oxygen

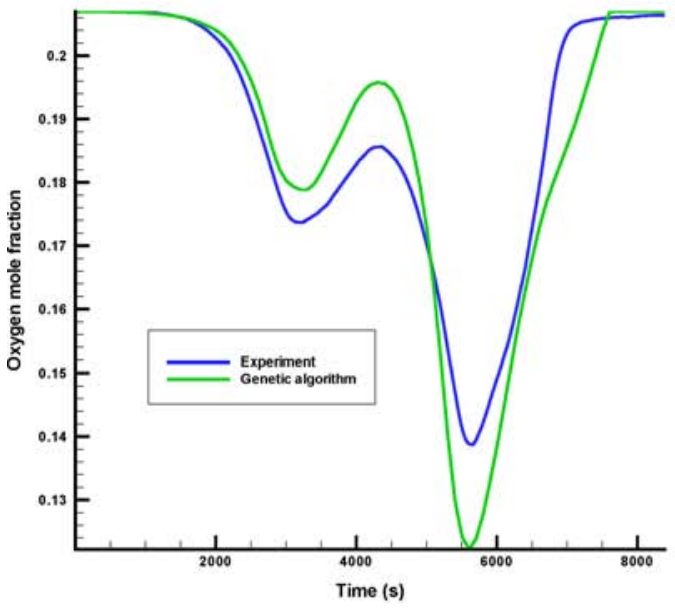

(c) \#2 - Oxygen

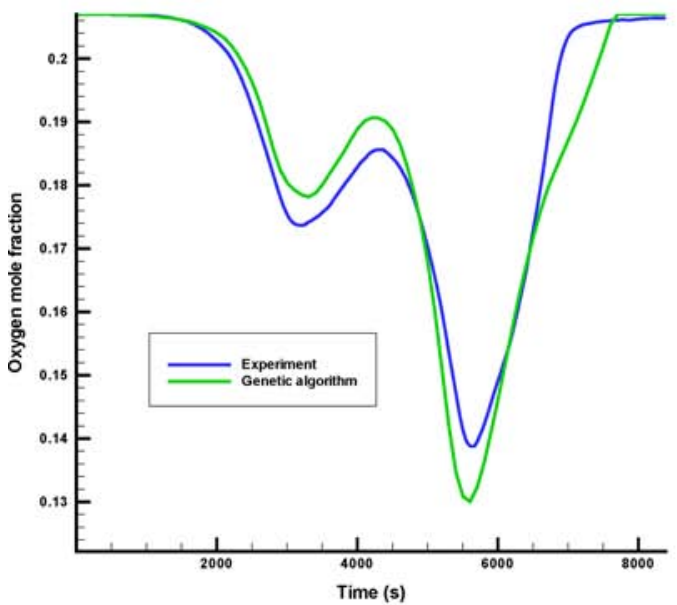

(e) \#58 - Oxygen

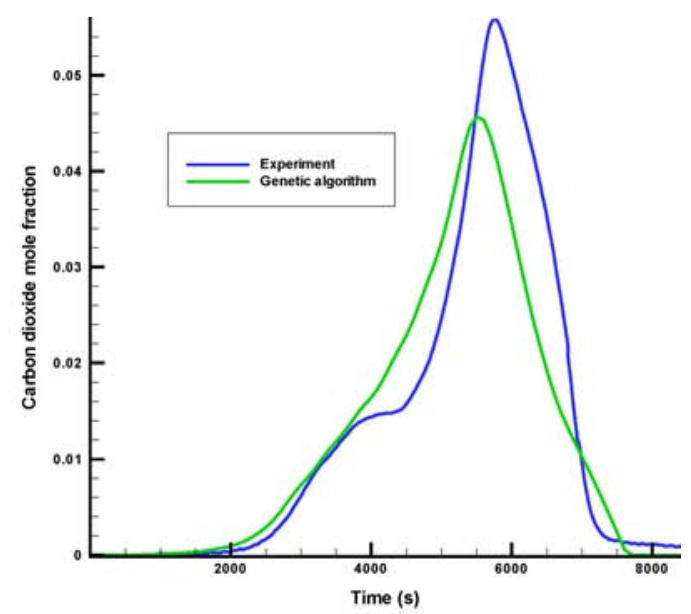

(b) \#1 - Carbon dioxide

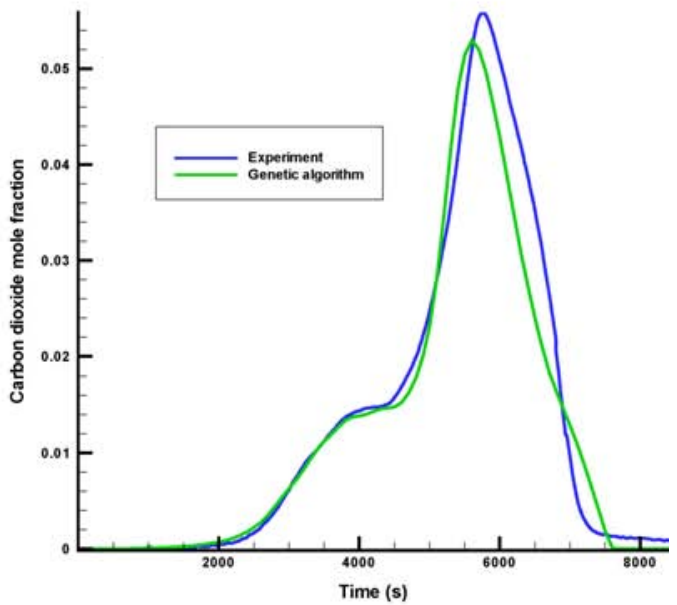

(d) \#2 - Carbon dioxide

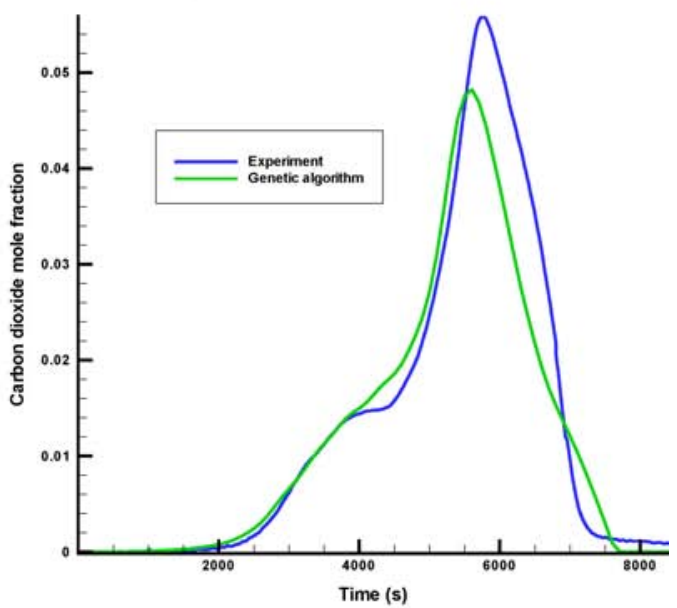

(f) \#58 - Carbon dioxide

Figure 7. Comparison between experimental results and numerical results from genetic algorithm for both objective functions: (a) solution 1, oxygen consumption; (b) solution 1, carbon dioxide production; (c) solution 2, oxygen consumption; (d) solution 2, carbon dioxide production ; (e) solution 58, oxygen consumption; and (f) solution 58, carbon dioxide production.

$$
\tau=A \exp \left(-\frac{E_{\mathrm{a}}}{R T}\right)\left[\mathrm{O}_{2}\right][\mathrm{F}]
$$

where $\tau$ is the reaction rate, $A$ the pre-exponential factor, $E_{\mathrm{a}}$ the activation energy, $R$ the gas constant, $T$ the temperature, $\left[\mathrm{O}_{2}\right]$ the oxygen concentration, and $[\mathrm{F}]$ the fuel concentration. All

the concentrations are defined over the system volume, including solid and pore space. For the reaction that does not involve oxygen, the reaction rate is expressed as

$$
\tau=A \exp \left(-\frac{E_{\mathrm{a}}}{R T}\right)[\mathrm{F}]
$$




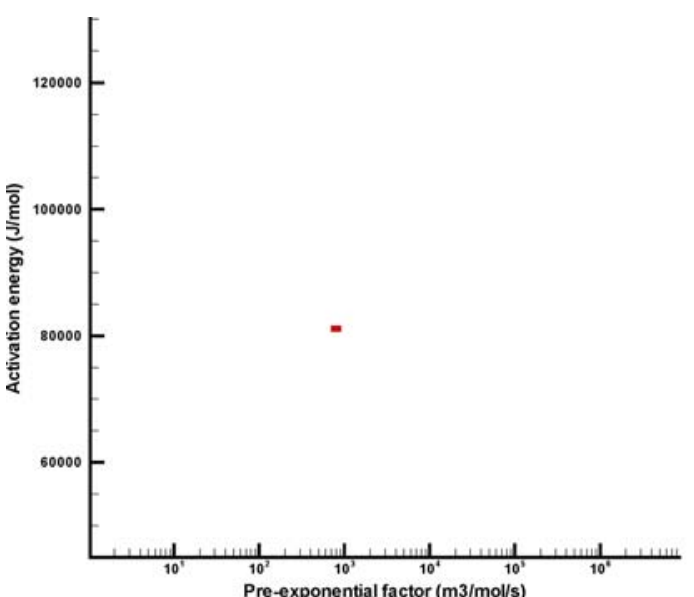

(a) $R_{3}$

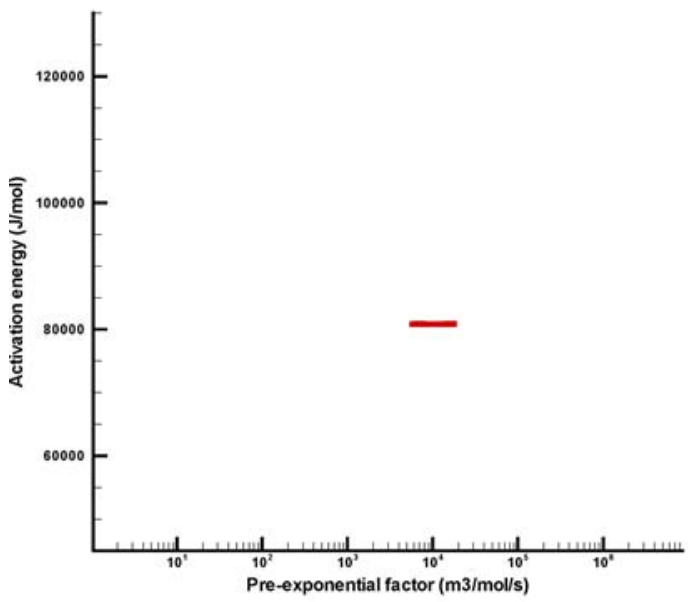

(c) $R_{5}$

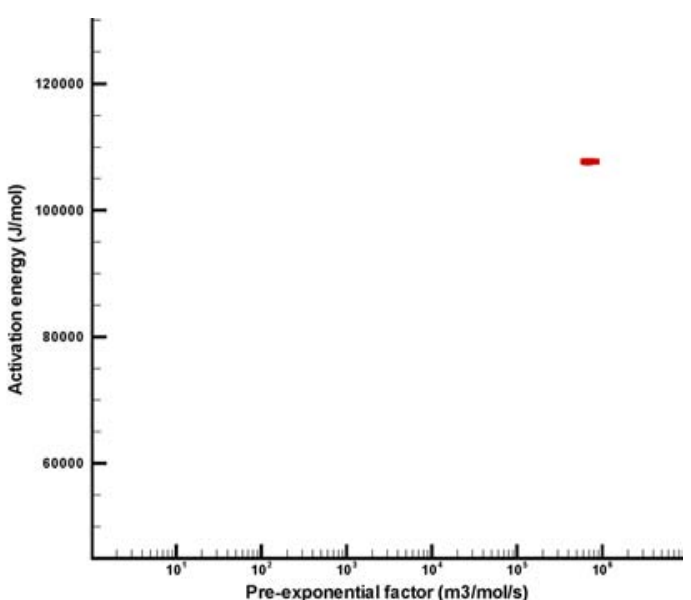

(b) $R_{4}$

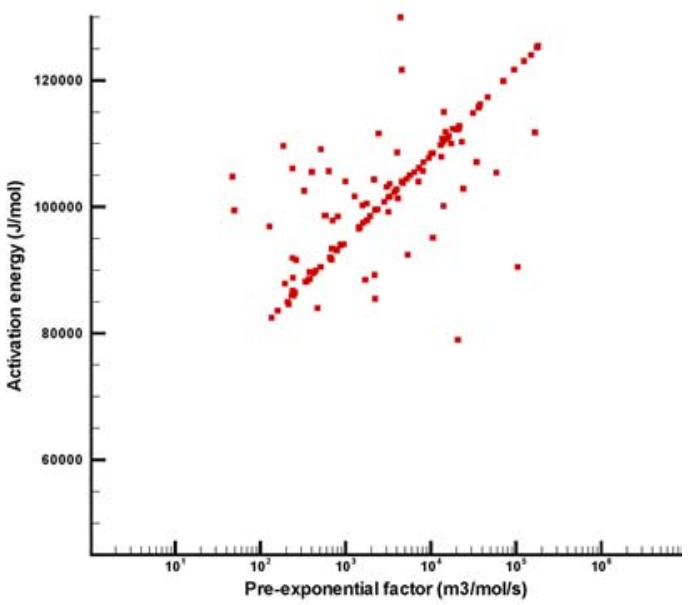

(d) $R_{6}$

Figure 8. Activation energy versus pre-exponential factor for (a) reaction $R_{3}$, (b) reaction $R_{4}$, (c) reaction $R_{5}$, and (d) reaction $R_{6}$.

Table 5. Ranges of Kinetic Parameters for Oxidation Reactions

\begin{tabular}{ccc} 
reaction & activation energy, $E(\mathrm{~J} / \mathrm{mol})$ & pre-exponential factor, $A(1 / \mathrm{s})$ \\
$\mathrm{R}_{3}$ & $81100-81160$ & $760-840$ \\
$\mathrm{R}_{4}$ & $107550-107750$ & $6 \times 10^{5}-8.5 \times 10^{5}$ \\
$\mathrm{R}_{5}$ & $80820-80850$ & $6 \times 10^{3}-1.6 \times 10^{4}$ \\
$\mathrm{R}_{6}$ & $80000-125000$ & $10^{2}-10^{6}$ \\
\hline
\end{tabular}

The first reaction we consider is the cracking reaction. A portion of the $\mathrm{C}_{50+}$ component, called $\mathrm{C}_{50+(\mathrm{c})}$, is transformed to methane and solid coke. The second reaction is the coke combustion. The third set of reactions represents the combustion of the light components. Light components are components up to $\mathrm{C}_{50+}$. The fourth set of reactions corresponds to the partial oxidation of light components. This reaction leads to new oxidized components: $\mathrm{C}_{2 \mathrm{ox}}-\mathrm{C}_{11 \mathrm{ox}}$ $\mathrm{C}_{12 \mathrm{ox}}-\mathrm{C}_{16 \mathrm{ox}}, \mathrm{C}_{17 \mathrm{ox}}-\mathrm{C}_{21 \mathrm{ox}}, \mathrm{C}_{22 \mathrm{ox}}-\mathrm{C}_{27 \mathrm{ox}}, \mathrm{C}_{28 \mathrm{ox}}-\mathrm{C}_{35 \mathrm{ox}}$, and $\mathrm{C}_{36 \mathrm{ox}}-$ $\mathrm{C}_{49 \mathrm{ox}}$. The fifth set of reaction is the combustion of the light oxidized components $\left(\mathrm{C}_{50+}\right)$. Finally, the sixth set of reactions depicts the oxidation of heavy components $\left(C_{50+(c)}\right.$.

Compared to the initial oil description coming from the thermodynamic analysis, the final oil composition includes seven more components. We decide to set the properties of $\mathrm{C}_{50+(\mathrm{c})}$ as the properties of $\mathrm{C}_{50+}$. We consider that $\mathrm{C}_{50+(\mathrm{c})}$ is the fraction of the original $\mathrm{C}_{50+}$ that can be cracked. Also, oxidized components are known to be less volatile than the nonoxidized counterparts. Because of the lack of data on such components, critical properties and acentric factors are tuned to ensure that they are nonvolatile. We are aware that simulations result could be quite sensitive to these properties. However, as far as we know, it is impossible to measure such properties for such polar components that temporarily take place in the oil. On the other hand, as simplest approach, we could have considered those components as solid components. But, because we know they play an important role by modifying fluid properties, such as increasing the viscosity, ${ }^{43}$ we think it is important to include them as fluid components. The properties are presented in Table 2.

Stoichiometry is calculated according to the atomic description of each component. For oxidation reaction, the ratio between $\mathrm{CO}_{2}$ and $\mathrm{CO}$ concentration is given as a constant parameter, according to experimental observations. Kinetic parameters of this reaction mechanism and the methodology are presented in the next sections.

Modeling the Cracking Reaction. The so-called reaction $\mathrm{R}_{1}$ is a cracking reaction. In addition to the original oil description, component $\mathrm{C}_{50+(\mathrm{c})}$ has been introduced. Since $\mathrm{C}_{50+(\mathrm{c})}$ is defined from the original $\mathrm{C}_{50+}$, we assume that

$$
z_{\mathrm{C}_{50+(\mathrm{c})}}=\alpha z_{\mathrm{C}_{50+(\mathrm{c})}} \quad \text { with } \quad \alpha \in[0,1]
$$

where $z_{\beta}$ is the mole fraction of component $\beta$. 
In order to get kinetic parameters for these reactions, experimental data from RUN 10 are used. Recall that RUN 10 is a two-stage experiment. The first stage is performed under nitrogen in order to crack the oil into solid coke. Then, a new classical experiment under oxygen is made by using the resulting coke sample.

We only consider the one-objective function built on methane production for $\mathrm{R}_{1}$ characterization. We are looking for the pre-exponential factor $(A)$, the activation energy $(E)$, and $\alpha$. We use the one-objective version of the genetic algorithm. We use a population size of 25 and 50 generations. A comparison between experimental results and numerical results is shown in Figure 2. The numerical results reproduce the experimental results fairly well. The amplitude and the position of the main peak are conserved, which is important physically. Despite this good match, the genetic algorithm did not return kinetic parameters that lead to a close match in the first and final part of the peak, which probably indicates that the kinetic model is missing some sensitive features.

Figure 3 shows the evolution of the parameters over the generations. We can see that the algorithm obtains the final parameters at the 21 st iteration. The final values are summarized in Table 3.

Modeling the Coke Combustion Reaction. Reaction $\mathrm{R}_{2}$ is the coke combustion reaction. The second stage of the RUN 10 experiment is used to build the objective function. We assume that the initial quantity of coke corresponds to the final quantity of coke produced from the previous numerical optimization. We also suppose that the reactivity of coke formed under nitrogen is essentially the same as the reactivity of coke formed under oxygen. In reality, coke production is dependent on the thermochemical conditions. The coke surface may differ, depending on the atmosphere under which it was formed. Hence, the reactivity of coke could change, because the oxidation coke is a heterogeneous reaction, as discussed elsewhere. ${ }^{44}$ Some authors go so far as to incorporate different coke species in their reaction sequences (see, for instance, the work of $\mathrm{Wu}$ and Fulton ${ }^{45}$ and Castanier and Brigham ${ }^{46}$ ). For this analysis, the inclusion of different coke species is not expected to produce significantly different results. However, the proposed work flow allows such assumptions.

Since carbon dioxide does not bring additional information to the optimization (the $\mathrm{O}_{2}$ and $\mathrm{CO}_{2}$ signals are perfectly aligned), we can use the single-objective version of the genetic algorithm. Accordingly, we only consider one objective function built on oxygen consumption for $\mathrm{R}_{2}$ characterization. We are attempting to determine the pre-exponential factor $(A)$ and the activation energy $(E)$. According to the experiment, we assume that $\left[\mathrm{CO}_{2}\right] /[\mathrm{CO}]=5$.

Again, population sizes of 25 and 50 generations are used. The comparison between experimental and numerical results is shown in Figure 4. The genetic algorithm finds kinetic parameters that lead to a good match between experimental and numerical results. The shape of the peak is not fully captured, but the main features (such as the amplitude and the position) are fairly well reproduced. The numerical solution slightly underestimates the oxygen consumption.

Figure 5 depicts the evolution of parameters versus the genetic algorithm generations. The algorithm finds reasonable magnitudes for the parameters within just five generations. The final values are given in Table 4 .

Modeling the Oxidation Reactions. The goal of the last stage is to determine the kinetic parameters, i.e., activation energies and pre-exponential factors for reactions $R_{3}-R_{6}$. Experimental data from RUN 12 are used. This experiment is a regular kinetic cell experiment performed under oxygen.

We consider oxygen and carbon dioxide gas analyses to build the kinetic model. The idea is to distinguish between partial and full oxidation reactions. Partial oxidation reactions consume oxygen without producing carbon dioxide and carbon monoxide, whereas full oxidation reactions produce both of them. We think it is important to consider both, because, otherwise, it is impossible to generate a comprehensive model that would include all the existing oxidation reactions. Accordingly, we perform the optimization based on two objective functions: the first is based on oxygen consumption and the other is based on carbon dioxide production. We assume, according to the experiments, that $\left[\mathrm{CO}_{2}\right] /[\mathrm{CO}]=2.5$ for $\mathrm{R}_{3}$ and $\mathrm{R}_{5}$, and $\left[\mathrm{CO}_{2}\right] /[\mathrm{CO}]=3.5$ for $\mathrm{R}_{6}$ and $\mathrm{R}_{7}$.

The multiobjective version of the genetic algorithm is used. We consider a population of 125 and compute 3000 generations. Figure 6 shows the value of the oxygen objective function versus the carbon dioxide objective function for different generations.

The convergence history shows several stages. First, the randomly generated first generation evolves to more localized and spotted solutions (100th generation). Then, the quality of the population gradually improves and a few members reach the desired Pareto front. At the same time, the population starts to spread, to give a more diversified population (500th generation). Finally, the population covers the Pareto front by spreading along it. At the 2000th generation, the population occupies a large part of the front and then again spreads along it, until the final generation. This last stage corresponds to an improvement of the extremes. The solution could have been improved again at the expense of the computation time. Indeed, the difference between the 2000th generation and the 3000th generation is small, but comes at great cost, in terms of computational time.

Figure 6 represents different generations in the plane objective function for $\mathrm{O}_{2}$; Figure 6 b represents a closer view of the Pareto front. The numbers 1, 2 and 58, correspond to members of the population. Figure 7 shows the comparison between experimental and numerical results for those members. The so-called solution 1 is the best solution, relative to oxygen data. Figure 7 a shows a very good match between numerical and experimental results, whereas the same set of parameters does not give a good match for carbon dioxide data, as shown in Figure $7 \mathrm{~b}$. Solution 2 is the opposite; it provides a very good match for carbon dioxide (Figure $7 \mathrm{~d}$ ), but a poor match for oxygen (Figure 7e). From the Pareto perspective, both solutions are acceptable, as well as all the other solutions on the Pareto front. However, from the scientific perspective, a good comprise solution is preferred, and solutions that penalize any one of the objectives too much are discarded. Thus, we examine solutions that are not located at or near the front extremes. Solution 58 is one of these solutions. Figures 7e and $7 \mathrm{f}$ show that this solution is a good compromise. It gives a fair match for both solutions and is an acceptable solution. Obviously, other sets of parameters are also acceptable. Theoretically, there is an infinite number of acceptable solutions.

Figure 8 depicts the kinetic parameters for the different reactions. Although kinetic parameters are very close to each other for reactions $R_{3}, R_{4}$, and $R_{5}$, and the parameters of 
reaction $\mathrm{R}_{6}$ are relatively spread along a quasi-straight line. Table 5 gives an overview of the solution ranges.

Reaction $R_{6}$, in this specific optimization problem, plays the role of an adjustment variable. The biggest differences among all the solutions, in terms of objective function, mainly come from the difference between the parameters of reaction $\mathrm{R}_{6}$. This might appear surprising initially; however, this is a direct result of the modeling approach and multiobjective optimization. The system we are trying to model is exceedingly complex. To make it computationally tractable, we must limit ourselves to a relatively small number of pseudo-components, each modeled to roughly capture the mean behavior of thousands of hydrocarbons and to a relatively small number (six) of reactions. Compared to the most commonly used models in the literature, we include more components and reactions, which we hope will help to better capture the reactions. Another improvement is that we use not only oxygen consumption but also the $\mathrm{CO}_{2}$ response. These two sources of information complement each other, and, at times, may be contradictory. This means that it is very possible for two different solutions to reach the same total optimal value: one can be slightly better in matching oxygen, whereas the other is slightly better in matching $\mathrm{CO}_{2}$. One global optimal solution can only be expected if the computational model captures the physics exactly (which is not the case). Therefore, the set of solutions, represented by the Pareto front, is to be expected. Overall, this approach leads to improved insight into the kinetics and the oil under study. Our recommendation to the user is to not select one of the solutions for reservoir simulations, but, instead, consider the set as representing uncertainty: multiple models can be implemented, tested, and integrated to give a range of possible reservoir behaviors. When more reservoir information become available, this range may be narrowed further.

\section{CONCLUSION}

In a previous paper, ${ }^{11}$ we proposed to model the kinetic cell experiment by using a new simulator that is able to, among other things, take into account all of the couplings, spatial effects, and phase changes.

In this study, we described an original way to determine kinetic parameters from kinetic cell experiments by using the kinetic cell simulator. We decided to couple it with a multiobjective genetic algorithm derived from the NSGA-II. This method allows us to consider many types of data, instead of just oxygen data, as is usually done (so far), and remove some experimental constraints, such as the linear temperature rise.

As an example, we applied the method to a kinetic cell experiment. We proposed an original six-reaction mechanism, based on a literature review and our experience. The kinetics are then built on oxygen and carbon dioxide data from previous observations. Based on genetic algorithm results, we provide set of solutions to characterize the kinetics. We clearly show the existence of many solutions, depending on the multiobjective criteria.

In future work, it is necessary to investigate why objective functions built on oxygen data compete with those built on carbon dioxide data. We speculate that this is a consequence of either an incomplete reaction mechanism and/or the masstransport model. To fully understand this situation, detailed comparisons between numerical simulations and combustion tube experiments are needed. The combustion tube simulator must contain a full set of equations that takes into account all of the possible mechanisms, multiphase and multicomponent flow and transport, and heat and mass transfers, relative to phase changes.

\section{AUTHOR INFORMATION}

\section{Corresponding Author}

*E-mail: alexandre.lapene@total.com.

\section{Notes}

The authors declare no competing financial interest.

${ }^{\ddagger}$ Currently at TOTAL E\&P, Pau, France.

\section{ACKNOWLEDGMENTS}

The authors would like to thank TOTAL SA for its financial support and Schlumberger for the postdoctoral fellowship of A.L.

\section{REFERENCES}

(1) Bousaid, I.; Ramey, H. Oxidation of Crude Oil in Porous Media. SPE J. 1968, Paper No. SPE 1937.

(2) Weijdema, J. Studies on the Oxidation Kinetics of Liquid Hydrocarbons in Porous Media with Regard to Subterranean Combustion. Erdol Kohle. Erdgas Pet. 1968 (September), 520-526.

(3) Dabbous, M.; Fulton, P. Low-Temperature Oxidation Reaction Kinetics and Effects on the In-Situ Combustion Process. SPE J. 1974, 14 (June), 253-262.

(4) Thomas, G.; Buthod, A.; Allag, O. An Experimental Study of the Kinetics of Dry, Forward Combustion: Final Report; U.S. Department of Energy, Springfield, VA, February 1979.

(5) Burger, J.; Sahuquet, B. Chemical Aspects of In-Situ Combustion-Heat of Combustion and Kinetics. SPE J. 1972, 12 (October), 410-422.

(6) Fassihi, M.; Brigham, W.; Ramey, H. Reaction Kinetics of In Situ Combustion-Part 1. Observations. SPE J. 1984, 399-407 (Paper No. SPE-8907-PA).

(7) Mamora, D.; Ramey, H.; Brigham, W.; Castanier, L. Kinetics of In Situ Combustion. Fossil Energy, DOE Report No. DOE/BC/14600-51, July 1993.

(8) Moore, R. New Strategies for In-Situ Combustion. J. Can. Pet. Technol. 1993, 32, 11-13.

(9) Bae, J. Characterization of Crude Oil for Fireflooding Using Thermal Analysis Methods. Soc. Pet. Eng. J. 1977, 211-217.

(10) He, B.; Chen, Q.; Castanier, L.; Kovscek, A. Improved In-Situ Combustion Performance with Metallic Salt Additives. Presented at the SPE Western Regional Meeting, Irvine, CA, March 30-April 1, 2005; Paper No. SPE-93901-MS.

(11) Lapene, A.; Debenest, G.; Quintard, M.; Castanier, L.; Kovscek, A.; Gerritsen, M. Kinetics oxidation of heavy oil. 1. A compositional and full equation of state model. Energy Fuels 2011, 25, 4886-4895.

(12) Fassihi, M.; Brigham, W.; Ramey, H. Reaction Kinetics of In Situ Combustion-Part 2. Modeling. SPE J. 1984, 24, 408-416 (Paper No. SPE-9454-PA).

(13) Cinar, M.; Castanier, L.; Kovscek, A. Isoconversional Kinetic Analysis of the Combustion of Heavy Hydrocarbons. Energy Fuels 2009, 23 (8), 4003-4015.

(14) Khansari, Z.; Gates, I. D.; Mahinpey, N. Low-temperature oxidation of Lloydminster heavy oil: Kinetic study and product sequence estimation. Fuel 2014, 115, 534-538.

(15) Lapene, A.; Castanier, L.; Debenest, G.; Quintard, M.; Kamp, A.; Corre, B. Effects of Steam on Heavy Oil Combustion. SPE Reservoir Eval. Eng. 2009, 12 (4), 508-517.

(16) Athan, T. W.; Papalambros, P. Y. A note on weighted criteria methods for compromise solutions in multi-objective optimization. Eng. Optim. 1996, 27, 155-176.

(17) Elliot, L.; Ingham, D.; Kyne, A.; Mera, N.; Pourkashanian, M.; Wilson, C. Multi-objective gentic algorithm for calculating the reaction 
rate coefficients for hydrogen combustion. Ind. Eng. Chem. Res. 2000, 42, 1215.

(18) Gopal, R.; Satyanarayana, V.; Prashant, K. NSGA-II for multiobjective optimization of pervaporation process: Removal of volatile organics from water. Ind. Eng. Chem. Res. 2009, 48, 15431550.

(19) Bhaskar, V.; Gupta, S. K.; Ray, A. K. Applications of multiobjective optimization in chemical engineering. Rev. Chem. Eng. 2006, 16, 1 .

(20) Marler, R. T.; Arora, J. S. Survey of multi-objective optimization methods for engineering. Struct. Multidiscip. Optim. 2004, 26, 369395.

(21) Schaffer, J. D. Multiple Objective Optimization with Vector Evaluated Genetic Algorithms. In Proceedings of the 1st International Conference on Genetic Algorithms (ICGA), Pittsburgh, PA, July 1985; pp 93-100.

(22) Horn, J.; Nafpliotis, N.; Goldberg, D. E. A niched Pareto genetic algorithm for multiobjective optimization. In Proceedings of the First IEEE Conference on Evolutionary Computation, 1994; pp 82-87.

(23) Zitzler, E.; Thiele, L. Multiobjective evolutionary algorithms: A comparative case study and the strength pareto approach. IEEE Trans. Evol. Comput. 1999, 3 (4), 257-271.

(24) Zitzler, E.; Marco, L.; Lothar, T. SPEA2: Improving the strength Pareto evolutionary algorithm, Computer Engineering and Networks Laboratory (TIK) Report 103, 2001.

(25) Srinivas, N.; Deb, N. Multi-objective function optimization using non-dominated sorting genetic algorithms. Evol. Comput. 1995, 2 (3), 221-248

(26) Deb, K.; Agarwal, S.; Meyarivan, T. A fast and elitist multiobjective genetic algorithm: NSGA-II. Evol. Comput. 2002, 6 (2), 182-197.

(27) Michalewicz, Z. Genetic Algorithms + Data Structures = Evolution Programs; Springer-Verlag: Berlin, 1994.

(28) Eshelman, L. J.; Schaffer, J. D. Real-Coded Genetic Algorithms and Interval Schemata. Found. Genet. Algorithms 1993, 2, 187-202.

(29) Sefrioui, M. Algorithmes Evolutionnaires pour le calcul scientifique. Application l'électromagnétisme et à la mécanique des fluides numériques. Ph.D. Thesis, Université de Paris 6, Paris, France, 1998.

(30) Fogel, D. Evolutionary Computation: Toward a New Philosophy of Machine Intelligence; IEEE Press: Piscataway, NJ, 1995.

(31) Janikow, C.; Michalewicz, Z. An Experimental Comparison of Binary and Floating Point Representations in Genetic Algorithms. In Proceedings of the 4th International Conference on Genetic Algorithms (ICGA), San Diego, CA, July 1991; pp 31-36.

(32) Kuhlman, M. Expanded uses of Nitrogen, Oxygen and Rich Air for Increased Production of Both Light Oil and Heavy Oil. SPE J. 2004, Paper No. SPE 86954.

(33) Freitag, N.; Verkoczy, B. Low-Temperature Oxidation of Oils in Terms of SARA Fractions; Why Simple Reaction Models Don't Work. J. Can. Pet. Technol. 2005, 44 (February), 54-60.

(34) Freitag, N. P.; Exelby, D. A SARA-based model for simulating the pyrolysis reactions that occur in high-temperature EOR processes. J. Can. Pet. Technol. 2006, 45, 38-44.

(35) Ren, Y.; Freitag, N.; Mahinpey, N. A simple kinetic model for coke combustion during an in situ combustion (ISC) process. J. Can. Pet. Technol. 2007, 46, 47-53.

(36) Verma, V. B.; Reynolds, A. C.; Thomas, G. W. A Theoretical Investigation of Forward Combustion in a One-Dimensional System. In Proceedings of the SPE Annual Fall Technical Conference and Exhibition, Houston, TX, October 1-3, 1978; Paper No. SPE-7526MS.

(37) Akin, S.; Bagci, S.; Kok, M. Experimental and Numerical Analysis of Dry Forward Combustion with Diverse Well Configuration. Energy Fuels 2002, 16, 892-903.

(38) Crookston, R.; Culham, W.; Chen, W. A Numerical Simulation Model for Thermal Recovery Processes. SPE J. 1979, 19, 37-58.

(39) Adegbesan, K. O.; Donnelly, J. K.; Moore, R. G.; Bennion, D. W. Low-Temperature Oxidation Kinetic Parameters for In-Situ
Combustion: Numerical Simulation. SPE Reservoir Eng. 1987, 2, $573-582$.

(40) Kumar, M. Simulation of Laboratory In-Situ Combustion Data and Effect of Process Variations. SPE J. 1987, Paper No. 16027.

(41) Freitag, N.; Exelby, D. A SARA-Based Model for Simulating the Pyrolysis Reactions that Occur in High-Temperature OER Processes. J. Can. Pet. Technol. 2006, 45 (March), 38-44.

(42) Ren, Y.; Freitag, N.; Mahinpey, N. A Simple Kinetic Model for Coke Combustion During an In Situ Combustion (ISC) Process. Presented at the Canadian International Petroleum Conference, June 79, 2005.

(43) Fassihi, M. R.; Meyers, K. O.; Basile, P. F. Low temperature Oxydation of Viscous Crude Oils. SPE Reservoir Eng. 1990, 5, 609616.

(44) Cinar, M.; Castanier, L. M.; Kovscek, A. R. Combustion Kinetics of Heavy Oils in Porous Media. Energy Fuels 2011, 25, 4438-4451.

(45) Wu, C.; Fulton, P. Experimental simulation of the zones preceding the combustion front of an in-situ combustion process. SPE J. 1971, 11, 38-46.

(46) Castanier, L.; Brigham, W. Upgrading of crude oil via in situ combustion. J. Pet. Sci. Eng. 2003, 39, 125-136. 